\title{
The paradox role of caspase cascade in ionizing radiation therapy
}

\author{
Najmeh Rahmanian ${ }^{1,2}$, Seyed Jalal Hosseinimehr ${ }^{2^{*}}$ (D) and Ali Khalaj ${ }^{3}$
}

\begin{abstract}
Radiotherapy alone or in combination with chemotherapy/surgery is widely used for treatment of cancers. It reduces tumor growth and prevents metastasis. While ionizing radiation activates caspase cascade resulted in apoptosis in cancer cells, it also stimulates tumor cell re-population that leads to reduce the effectiveness of the radiation therapy. This review describes the mechanisms for paradox role of caspase cascade in cancer therapy and discusses the logical and practical strategies for improvement the therapeutic index of radiotherapy through enhancement of radiosensitivity and decreasing the rate of tumor recurrence.
\end{abstract}

Keyword: Caspase, Radiotherapy, Cancer, Treatment, Induction

\section{Background}

Radiotherapy is one of the helpful clinical procedure for treatment of different types of human malignancies especially lung, thyroid, breast, colon, prostate and brain cancers. Nearly $50 \%$ of all cancerous patients are receiving ionizing radiation (IR) at some stages of their treatments $[1,2]$. Following irradiation, cancer cell death may occur mainly through necrosis, autophagy and apoptosis of which autophagy has more complex role and might promote cell survival [3-5]. IR prolongs patient's survival through decreasing proliferative capacity and killing tumor cells [6-8]. However, re-population of tumor cells during or after radiotherapy is an important obstacle to achieve the desired response $[9,10]$. Since death of high percent of tumor cell is a desirable response in radiotherapy regimen, identification of the limiting factors such as cellular proliferation and intrinsic radioresistance are very important in cancer treatment $[6,9,11,12]$. Escaping from programmed cell death or apoptosis is one of the popular theories that explain cancer cell radioresistance $[1,13]$. Caspase cascade as an apoptosis mediator in radiation therapy has been described to activate signal transduction pathways and expression of survival proteins [14]. In this review, the paradox role of caspase cascade in adjuvant therapy of the cancer by IR is discussed.

\footnotetext{
* Correspondence: sjhosseinim@yahoo.com

2Department of Radiopharmacy, Faculty of Pharmacy, Mazandaran University of Medical Sciences, Sari, Iran

Full list of author information is available at the end of the article
}

\section{Caspase cascade functions}

Caspases (cysteine-aspartic proteases, cysteine aspartases or cysteine-dependent aspartate-directed proteases) are a family of protease enzymes that have critical roles in controlling homeostasis in apoptosis and inflammation processes [6]. On the basis of the mechanisms of actions, caspases have been categorized into initiators (apical: CASP2, CASP8, CASP9 and CASP10) and effectors (executioner: CASP3, CASP6, and CASP7). It is believed that caspases are present as inactive monomeric precursor enzymes that must be dimerized for full activation [11, 13, 15-17].

\section{Apoptosis}

Apoptosis is a programmed cell death that is involving degradation of the cellular component such as nuclear DNA, the Golgi, endoplasmic reticulum (ER) and hydrolysis of mitochondrial networks by a group of cysteine proteases called caspase. A variety of stimuli including IR, chemotherapeutic drugs, death receptors-mediated processes like tumor necrosis factor $\alpha[\mathrm{TNF} \alpha]$, growth factor withdrawal, loss of cell adhesion (anoikis) and cytoskeletal damage might promote apoptosis pathway through activation of the caspase cascade [18].

\section{Apoptosis inhibition}

Caspase family have important roles in various diseases and it has been shown that caspase deficiency results in tumor development [19-21]. Suppression of caspase activation can be promoted by several proteins including: $\mathrm{Bcl}-2$, 
Inhibitors of Apoptosis Proteins family (IAPs) and Cytokine Response Modifier A (CrmA) [22, 23]. Bcl-2 is an antiapoptotic effector protein which prevents the distribution of pro-apoptotic proteins such as Bax in the mitocondria [24]. Human IAPs namely XIAP, c-IAPl, C-IAP2, NAIP, Livin and Survivin have been described [25]. CrmA prevents caspase dimerization for full activation. Generally, these groups of proteins inhibit cell death through the inhibition of caspase and suppression the activity of proapoptotic proteins like as Bax, Bad, Bim and Noxa and also by augmentation of the activity or expression of antiapoptotic proteins like as Bcl-2, IAPs and CrmA [26].

\section{Radiation-induced apoptosis}

Following exposure to IR, reactive oxygen species (ROS) and free radicals are generated which induce DNA damages. Double-Strand Breaks (DSBs), is the most abundant and toxic DNA damage which results from the exposure to one Gy of IR [27]. Following of DNA damage, cell cycle arrest and DNA repair are activated. Also two important pathways namely ATM-CHK2 (Ataxia Telangiectasia Mutated-Checkpoint Kinase 2) and ATR-CHK1 axis (Ataxia Telangiectasia and Rad3-related Checkpoint Kinase 1) are activated and induced by DSBs and DNA single-strand breaks (SSBs), respectively [12]. These pathways have overlapping functions and act in parallel with each other $[12,28]$. CHK2 and CHK1 phosphorylate different positions of the p53 which results in its dissociation from mdm2 (mouse double minute 2 homolog). P53 as a tumor suppressor has important role in initiation and prevention of the cancer. P53 has been named "guardian of the genome" because of its essential role in the selection of cell death or cell survival [29]. P53 activation regulates DNA repair processes and cell-cycle arrest that occurs at G1-S and G2-M transitions [3, 27]. Actually, the degree of DNA damage-repair is very prominent to determine whether cell survival or cell death [30]. Briefly, the p53 transcription factor responds to numerous cellular stresses and eliminates cells containing oncogenic lesions or damaged DNA, thus preventing tumor development [12]. Defective DNA repair results in promotion of aneuploidy and progression of cancer. The importance of p53 in sensitivity to radiation was discussed by several studies. For instance, resistance to radiation have been found in thymocytes lacking functional p53, whereas wild type p53 are extremely sensitive to radiation [31]. Moreover, radiosensitive apoptotic pathway is induced in colonic and leukemia malignant cells with overexpression of wild type p53 [32, 33]. In Summary, p53 expression has pivotal role in induction of p53-dependent apoptosis and cells with high p53 mRNA expression are more susceptible to radiation-induced apoptosis [34].

IR frequently induces intrinsic (mitochondrial mediated), extrinsic (death receptor mediated) and membrane (ceramide production) apoptotic pathways. Intrinsic and extrinsic apoptotic pathways are activated by p53 and membrane stress pathway is promoted by contribution of ceramide as a second messenger (Fig. 1) [35].

\section{Extrinsic apoptotic pathway}

In the extrinsic apoptotic pathway, a complex is formed between the death receptors such as CD95 (APO-1/Fas), TNF receptor 1 (TNFRI), TNF-related apoptosis-inducing ligand-receptor 1 (TRAIL-R1) and extracellular ligands including CD95 ligand (CD95L), lymphotoxin- $\alpha$ and TNFrelated apoptosis-inducing ligand (TRAIL-1). It should be noted that activation of $\mathrm{p} 53$ by radiation causes downstream transactivation of both death receptors and ligands $[35,36]$. Complex formation between the death receptors and their cognate death ligands results in receptor trimerization and clustering of the death domain receptors. Also, recruitment of an adaptor protein like as fas-associated death domain (FADD) mediated by Death Domain (DD) lead to the formation of the death inducing signaling complex (DISC) by interaction between pro-caspase 8 and FADD. The resulting complex activates caspase- 8 as a caspase initiator which in turn triggers executioner caspases 3 and 7 and as a consequence results in the cell death [17, 35].

\section{Intrinsic apoptotic pathway}

Apoptotic mitochondria pathway is regulated by $\mathrm{Bcl}-2$ family. Following p53 activation in response to a stress such as IR, PUMA (p53 Upregulated Modulator of Apoptosis) expression is results in the release of BAX a member of the Bcl-2 family. The Bcl-2 family may act either as antiapoptotic (e.g. Bcl-2, Bcl-xl) or pro-apoptotic (e.g. Bax, BAD). Bax expression leads to Mitochondrial Outer Membrane Permeabilization (MOMP) that results in release of the cytochrom $\mathrm{C}$ from mitochondria intermembrane space to cytoplasm [35]. Moreover, IR may increases the formation of $\mathrm{O}_{2}^{*}$ in mitochondria directly which in turn triggers the release of cytochrome $C$ [37]. Results of the recent studies suggest that cytochrom C, dATP and an adapter protein namely apoptotic protease-activating factor-1 (APAF-1) are involving in the formation of a large multimeric complex called apoptosome. Activation of the procaspase 9 through with apoptosome leads to the cell death.

\section{Membrane stress pathway}

In contrast to intrinsic and extrinsic pathways, membrane stress pathway is independent of p53 [38]. Release of Ceramid as a second messenger is necessary to initiate this pathway. Ceramid can be formed through two different ways. Oxidative damages of ROS on lipid membrane results in activation of sphingomyelinase which in turn hydrolyze sphingomyelin of the membrane to ceramide $[35,39]$. Also the high dose of IR induces DSBs which activates the synthesis of ceramide [40]. Ceramide 


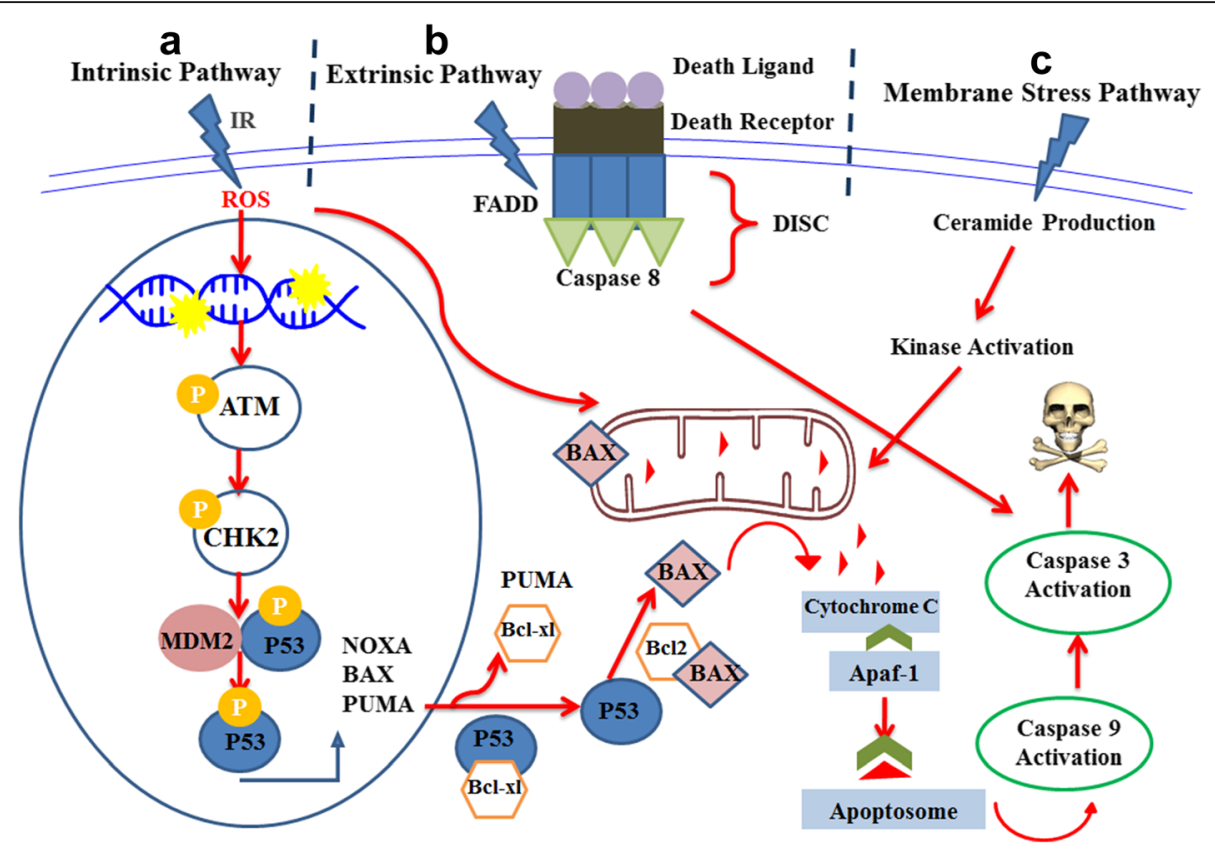

Fig. 1 A summary of extrinsic, intrinsic and membrane stress apoptotic pathways. a DNA damages lead to activation of p53 that promotes the expression of pro-apoptotic proteins such as BAX and consequently permeabilization of the outer membrane of mitochondria and release of cytochrome $\mathrm{C}$ followed by formation of a large multieric complex namely Apoptosom through participation of cytochrome C, dATP and apoptotic protease-activating factor-1 (APAF-1). b Activation of p53 by ionizing radiation leads to downstream transactivation of death receptor and death ligand that trigger extrinsic apoptotic pathway followed by complex formation between death receptor and its cognate ligand. Complex formation results in receptor trimerization and consequently formation of death inducing signal complex (DISC) by participation of FADD (Fas-associated death domain) mediated by DD (death domain). c Apoptosis might be prompted by production of ceramide as a second messanger which is activated by double strand breaks (DSBs) and reactive oxygen species (ROS) and as a result activation of sphingomyelinase followed by hydrolysis of sphyngomyelin and release of ceramide. The outcome of apoptosis is caspase activation which results in cell death due to production of apoptosome, death inducing signaling complex (DISC) and ceramide in intrinsic, extrinsic and memberane stress apoptotic pathways, respectively

promotes MAP/ERK (Mitogen Activated Protein/Extracellular Signal-Regulated Kinase) (MEKK) pathway which in turn activates Mitogen-Activated Protein Kinase 8 (MAPK8) and of the effector caspases-1, -3 and -6 that promote the cell death pathway [35].

\section{Suppression of radiation-induced apoptosis}

IR induces multiple pro-survival signaling pathways through activation of ERK, c-Jun N-terminal Kinase (JNK), p38 MAPK and overexpression of COX-2 that can suppress apoptosis and reduce the cytocoxicity of radiation in radioresistance cancer cells. The mechanisms of these survival signaling pathways induce cell viability and inflammation are as follows:

\section{Radiation- induced ERK1/2 pathway}

IR activates human epidermal growth factor receptor (HER) signaling pathway which consists from four plasmamembrane bound receptor tyrosine kinase HER1, HER2, HER3 and HER4 [41]. IR mimics the behavior of EGF and induces HER dimerization which is followed by autophosphorylation of several tyrosine residues in the c-terminal of the regulatory tail of the receptor. HER activation stimulates Ras/Raf/MEK/ERK pathways through the exchange of GDP bound to Ras for GTP [35]. MEK activates ERK1/2 through phosphorylation of threonine and tyrosine which in turn inactivate apoptosis through inhibition of some pro-apoptotic proteins such as Bim, Bad, caspase 9. It also enhances expression of anti-apoptotic proteins such as Mcl-1, Bcl-xl. In summary radiation-induced activation of ERK1/2 signaling results in apoptosis suppression in irradiated cell by enhancing the activity/expression of antiapoptotic proteins such as $\mathrm{Bcl}-\mathrm{xl}$ and prevention of the activity of pro-apoptotic proteins [42-45].

\section{Radiation-induced Akt signaling pathway}

Upon HER hetrodimerization and autophosphorylation, PI3K/AKT1 and Ras/Raf/MAPK pathways are activated. AKT is a vital pro-survival factor that suppresses the apoptotic signaling pathway and leads to activation of pro-survival pathways and cell development [46]. Following HER dimerization and autophosphorylation of tyrosines in the regulatory intracellular domains of the receptor, six docking sites are formed [47]. Binding of the p85 regulatory subunit of the class 1 phosphatidylinositol 3-kinases (PI3K) to docking sites recruits the p10 subunit 
of PI3K as a catalytic subunit to form fully activated phosphatidylinositol 3-kinase (PI3K) enzyme. PI3K converts phosphatidylinositol-4,5-biphosphate (PIP2) to phosphatidylinositol $(3,4,5)$-triphosphate (PIP3) which activates phosphoinositide-dependent kinase (PDK) [48]. AKT is activated at first through phosphorylation of Thr 308 present in its kinase domain by activated PDK1 and then by phosporylation of Ser 473 present in its Cterminal domain by PDK2 [42, 48]. Activated AKT negatively regulates apoptotic pathways at least through seven mechanisms. I) phosphorylation and inhibition of the pro-apoptotic proteins of $\mathrm{Bcl}-2$ family (e.g. Bad, Bax, Bim) [46] and inhibition of the expression of the pro-apoptotic proteins (Bim, Noxa) [49], II) phosphorylation of $\mathrm{NF}_{-} \mathrm{B}$ as a pro-survival transcription factor that leads to expression of the anti-apoptotic proteins including Bcl-2 and Bcl-xl. [50], III) activation of XIAP (X-linked inhibitor of apoptosis protein) as a pro-survival protein that inhibits caspase 3, 7, 9 and results in suppress apoptosis [51], IV) activation of m-TOR kinase signaling pathway and other pro-survival signaling pathway that results in activation of mcl-1 as an anti-apoptotic protein [52], V) direct inhibition of the pro-apoptotic transcription factor Foxo3a as a positive regulator which induces expression of pro-apoptotic proteins [53], VI) phosphorylation of glycogen synthase kinase which results in inhibition of apoptotic induction by this enzyme under hypoxia during radiation therapy [54], VII) direct activation of non-homologous end joining (NHEJ) as a pathway which repairs DSBs damages and results in enhanced cell survival [55]. In summary, all the above mentioned mechanisms can be activated by AKT signaling pathway, which results in cancer cell development in response to radiation [42].

\section{Radiation-induced JAK-STAT signaling pathway}

IR activates JAK-STAT signaling pathway by increasing in the phosphorylation of Janus-Associated kinase 2 (JAK-2) and consequently Signal Transducer and Activator of Transcription (STAT). Translocation of STAT to the cell nucleus increases the levels of $\mathrm{Bcl} 2 / \mathrm{Bcl}-\mathrm{xl}$ proteins that are leading to decrease caspase- 3 activity, tumor survival and radioresistant lung cancer cells. Niclosamide as an effective STAT3 inhibitor has shown to block effectively STAT3/Bcl2/Bcl-xl and to reduce the radioresistance in animal lung cancer xenografts $[56,57]$.

\section{Radiation-induced Cox-2 overexprresion}

Cyclooxigenases or prostaglandin synthases (COXs or PGH synthase) also known as COX-1, COX-2 and COX-3 are required enzymes for the formation of prostanoids including prostaglandins and thromboxane. Of three isozymes, COX-2 has aggressive behaviors in tumors and is overexpressed in a variety of malignant tumors such as melanoma and breast cancer [58, 59]. Moreover, IR increases the production of COX-2 proteins. Several prosurvival pathways are mediated by COX-2 and result in tumor progression. Prostaglandin E2 (PGE2) is one of the main products of these pathways that has important role in cell proliferation, cell migration, tumor invasion and cell death [56]. PGE2 increases intracellular cAMP levels which activates protein kinase A (PKA) and phosphatidylinositol 3-kinase (PI3K) enzymes. PGE2 increases the level of $\mathrm{Bcl}-2$ in adenocarcinoma and activates MAPK pathway through transactivates EGFR by increase in amphiregulin levels as a well-known EGFR ligand [56, 60, 61]. Yamakie et al. reported that PGE2 activated sarcoma kinase in non-small cell lung cancer through phosphorylation and activation of STAT3 [62]. Briefly overexpression of COX-2 in cancer cells mediates several pro-survival pathways including; MAPK/ERK, JAK/STAT, PI3K/AKT that enhance expression of pro-survival proteins such as $\mathrm{NF}_{-\mathrm{K}} \mathrm{B}, \mathrm{Bcl}-2$ and $\mathrm{Bcl}-\mathrm{xl}$, IAP. It inhibits expression of pro-apoptotic proteins including Bad, Bax, and Bim that lead to inactivate caspase cascades and subsequently suppress apoptotic pathway. Therefore it seems that COX-2 inhibitors such as celecoxib might be useful to enhance the therapeutic index of chemoradiation through sensitization of tumor cells and as well as protection of normal cells to IR [56, 60,61]. Radiosensitivity effect of COX-2 inhibitors will discuss in next section.

\section{Activation of radiation-induced apoptosis: caspase inducers}

It is well known that the defects in caspase cascade activation lead to tumor progression and metastasis while its activation by compounds sensitizing tumor cells to IR result in induction of apoptosis, reduction in tumor size and control of cancer development. The amplification in expression of CASP3 protein after exposure to radiation induces the cell death through apoptotic pathway [63, 64]. It has been demonstrated that apoptotic receptor agonists such as monoclonal antibody ligands that bind specifically to TRAIL receptors (TNF-related apoptosis-inducing ligand) in combination with IR cause a synergistic apoptotic effect through the activation of caspase cascade pathway [65-68].

\section{Radiosensitizers}

Compounds known as radiosensitizers enhance therapeutic index of radiotherapy through inducing apoptosis. One of the most important reasons for the resistance to chemotherapy and /or radiotherapy is the presence of hypoxic cells in solid tumors because of insufficient blood supply to these tumors. Oxygen by formation of free-radical DNA damage increases the effectiveness of radiation and it is known as a potential radiosensitizer. Nitoaromatic and nitroheterocyclic compounds act as radiosensitizers by formation of nitro-anion radicals like oxygen. The synthesis and in vitro cytotoxicity of several dinitrophenyl derivatives of 5-fluorouracil [69, 70], 3-[(2,4-dinitrophenylamino)alkyl] 
derivatives of 5-fluorouracil [71], metronidazole tethered 5fluorouracil [72] as radiosensitizers have been described. These compounds had little or no aerobic cytotoxicity while showed high cytotoxicity and radiosensitizing effect under hypoxic conditions.

The radiosensitizing effects of luteolin have been investigated in H1299 and NCI-H460 non-small cell lung cancer. Results have shown that inhibition of the cyclindependent kinase 2 by luteolin led to the cell-cycle arrest and as a consequence activation of the apoptosis. Also luteolin could inhibit the function of $\mathrm{Bcl}-2$ in B-cell lymphoma 2 as a pro-apoptotic protein inhibitor and promote activation of caspase- $3,-8$ and -9 . It has been reported that combination of radiation and luteolin increased NSLC cell deaths and decreased tumor growth in nude mice bearing NCI-H460 cell xenograft [73]. Luteolin remarkably enhanced the radiosensitivity of gastric human tumors by a significant downregulation of PGE2 production and augmentation of the caspase activity simultaneously [74]. Plumbagin a naphthoquinone derivative acts as a radiosensitizer in numerous cancer cell lines like melanoma and cervix cancer. The combination of plumbagine and 2 Gy of radiation has shown synergism effects and was more effective in induction of cell deaths as compared to 10 Gy of radiation alone. Plumbagine activates caspase 3 and suppresses $\mathrm{Bcl}-2$ and $\mathrm{Bcl}-\mathrm{x}$ as anti-apoptotic molecules without any changes in expression of Bax as pro-apoptotic protein. In summary, the combination use of sensitizing agent and IR has more effective in cell growth inhibition as compared to the use of only higher dose of IR [75].

\section{Neutralization of IAPs (inhibitors of apoptosis proteins)}

Recently several approaches for the cancer treatment are proposed in induction of apoptosis and increases the radiosensitizing effects through neutralization of IAP. One of the most important strategies for stimulation of caspase activation and sensitization of cancer cells to apoptosis is design and development of a new class of compounds mimicking endogenous IAP antagonists. By stimulation of apoptosis second mitochondria-derived activator of caspase (Smac) also known as DIABLO (direct IAP binding protein with low $\mathrm{pI}$ ) is released from mitochondria into cytosol that antagonizes IAPs as XIAP, cIAP1 and cIAP2 and also Smac stimulates the activation of caspase 3 and subsequently promotes apoptosis pathway. Ala-Val-Pro-Ile (AVPI) tetrapeptide in Smac /DIABLO competes directly with a similar tetra peptide, Ala-Thr-Pro-Phe (ATPF) motif present in caspase 9 , and by binding to a domain in XIAP prevents its binding to caspases 3, 7 and 9 (Fig. 2) [76]. It has been proposed that the combination use of a Smac mimetic and radiation may sensitize cells to killing effects of radiation through neutralization of the activity of IAPs that result in overcomes apoptosis, causes the release of cytochrome c and triggers caspase-3 activation in the following of apoptosome complex formation [77-79].

Recently several Smac mimetics have been introduced to neutralize IAP proteins and eliminate resistance of lung, breast, prostate and colorectal carcinoma to IR [79]. For example, small molecule Smac mimetic Debio 1143 or SM-406 were shown to be a potent sensitizers of NSCLC cells to effects of IR-induced apoptosis through cleavages of caspasse-3, -8 and a decrease in IAPs level. Debio 1143 remarkably enhanced the radiosensitivity by autocrine TNF- $\alpha$ production in cancer cell lines (Fig. 2). It has been shown that the release of TNF- $\alpha$ activates bindings of caspases 3 and 8 to TNFRs and provokes interaction of the Fas-associating protein with a death domain (FADD)/ receptor interacting protein 1 (RIP1)/RIP3 which results in the death of cells by promotion of the apoptosis pathway. Furthermore it has been shown that the radiosensitization effects could be potentiated by increase in the drug concentration, incubation time and TNF- $\alpha$ stimulation [80]. A number of XIAP antagonists with nanomolar affinity to the baculovirus IAP repeat 3 (BIR3) domain of XIAP have been described which promote apoptosis in resistance cancer cell lines and inhibit the growth of tumors in a MDAMB-231 breast cancer mouse xenograft model [81]. Also it has been reported that the use of XIP antagonists increase the efficacy of radiotherapy by a significant decrease in the viability of gliobelastoma cells and increase $\gamma$-irradiation induced apoptosis by enhancement in cleavage of caspases 3 and 8 into active fragments [82]. BV6 is another small Smac mimetic-molecule that is radiosensitizer. BV6 is able to sensitize several glioblastoma cell lines to effects of radiation by stimulation of NF-kB activation, $\gamma$-irradiationtriggered caspase activation, cytochrom $\mathrm{C}$ release and increase in mitochondrial outer membrane permeabilization (MOMP) (Fig. 3) [83, 84]. It has been shown that the Smac mimetic LCL161 could increase the efficacy of radiotherapy in esophageal squamous cell carcinoma through the activation of caspase 8 and down regulation of IAP expression (Fig. 3) [85]. The efficacy of Smac mimetic SM164 in sensitization of breast carcinoma and head and neck squamous cells to effects of IR has been demonstrated (Fig. 3) [86-88]. Mechanistic studies have revealed that exposure of carcinoma cells to SM164 and radiation results in induction of apoptosis by activation of caspase cascade pathway and inhibition of IAP [86].

Survivin is a unique member of IAP family that acts as an inhibitor of caspase cascade. High expression of survivin results in suppression of apoptosis which is strongly correlated with radioresistance in most human tumor cells. It has been suggested that inhibition of survivin results in radiosensitization in treated cancerous cells [89-91]. For instance, treatment of human epidermoid carcinoma cell line A431 with adenoviral-mediated wild-type p53, as a survivin antisense, resulted in radiosensitivity [92]. Attenuation of 


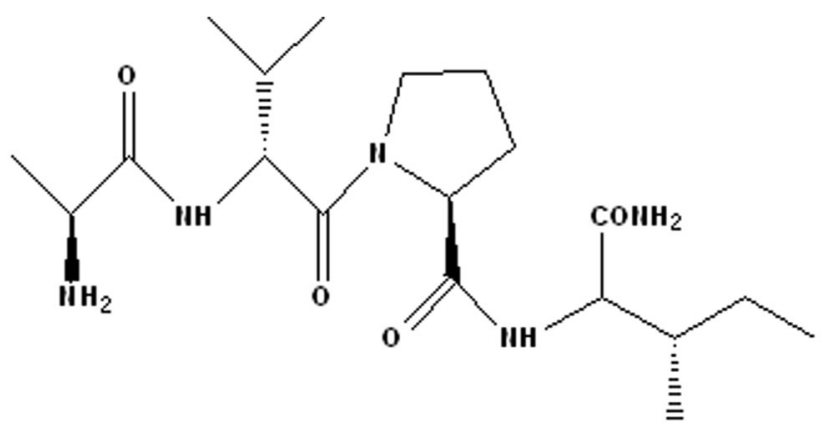

SMAC A VPI Peptide

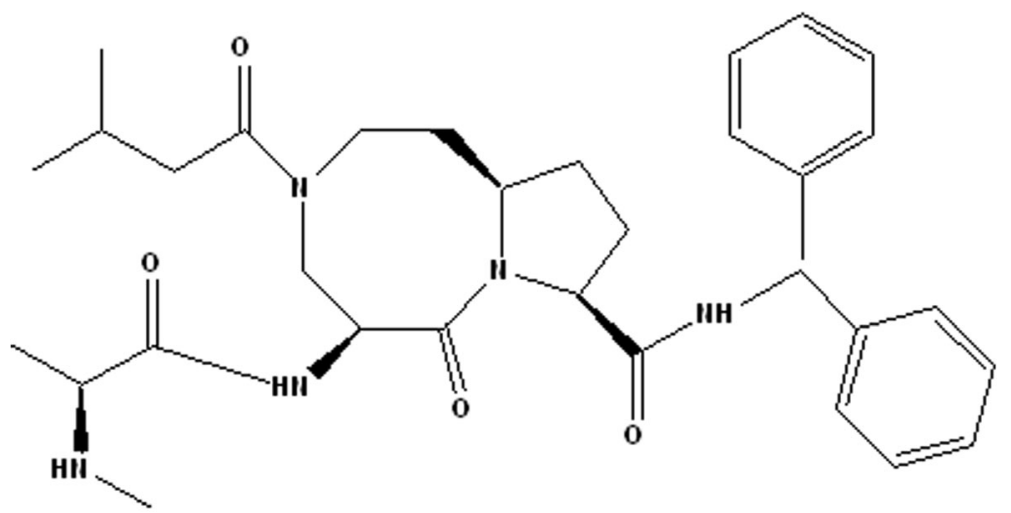

Debio 1143

Fig. 2 Chemical structures of Smac AVPI peptide (Second mitochondria-derived activator of caspase Ala-Val-Pro-lleu) and Debio 1143

survivin expression is also reported by treatment of human melanoma cells with a hammerhead ribozyme. Ribozyme expressing cells which have high sensitivity to effects of gamma radiation catalytic activity [93]. When siRNA was applied for downregulation of survivin expression in sarcoma and pancreatic cancer cell lines, there was an increase in caspase activity followed by a significant decrease in radioresistance. As a result this combination therapy perhaps be useful for the treatment of sarcoma and panceratic resistance carcinoma [94, 95].

Oxaliplatin is an anti neoplastic drug that is used for treatment of colorectal cancer. The combination of oxaliplatin and radiation is another logical strategy to control proliferation of the head and neck squamous cell carcinoma (HNSCC) by diminishing survivin expression and as a result induction of apoptosis through enhancement in caspase-3 activity. Oxaliplatin treatment markedly decreased expression of survivin in cancer cells. The cytotoxicity of oxaliplatin and radiation combination was greater than IR or oxaliplatin alone [96].

\section{Radiosensitizing effect of COX-2 inhibitor agents}

Several studies demonstrated that COX-2 has a key role in cell proliferation in cancer cells because its expression altering function/regulation of pro-apoptotic proteins. It is cleared that COX-2 selective inhibitor is correlated with better the tumor growth control and response to radiation [97]. A well-known mechanism for radiosensitivity activity of COX-2 inhibitor e.g celecoxib is induction of apoptosis through reduction of activity/expression pro-survival proteins such as survivin, $\mathrm{Bcl}-2, \mathrm{Bcl}-\mathrm{xl}$, upregulation the level of P53, amplifying G2/M phase arrest, activation of intrinsic and extrinsic pathways of apoptosis and increase the level of expression/activation of caspase 8, caspase 9 [56, 60]. Grimes et al. showed nimesulide, a COX-2 selective inhibitor, has radiosensitivity activity in A549 non-small cell lung cancer cells and in nude mice bearing A549 tumor xenografts. Nimesulide inhibited NF-KB activity, with anti-apoptotic effect, that led to down-regulate the superoxide dismutase (MnSOD) with anti-oxidant activity, and surviving. Combination treatment with nimesulide and 30 Gy fractionated radiation resulted to diminish in tumor size compared with radiation only [98]. In esophageal squamous cell lines TE2 and T.Tn, the combination of radiation and celecoxib enhanced the radiotherapy efficacy through arresting the G2/M phase, inhibiting the expression of prostaglandin that has radio-protective effect. Celecoxib inhibited the DNA repair process and enhanced the expression/activation of caspase 8 and caspase 3 [99]. Radiosensitivity effect of diclofenac in COX-2 overexpressed 


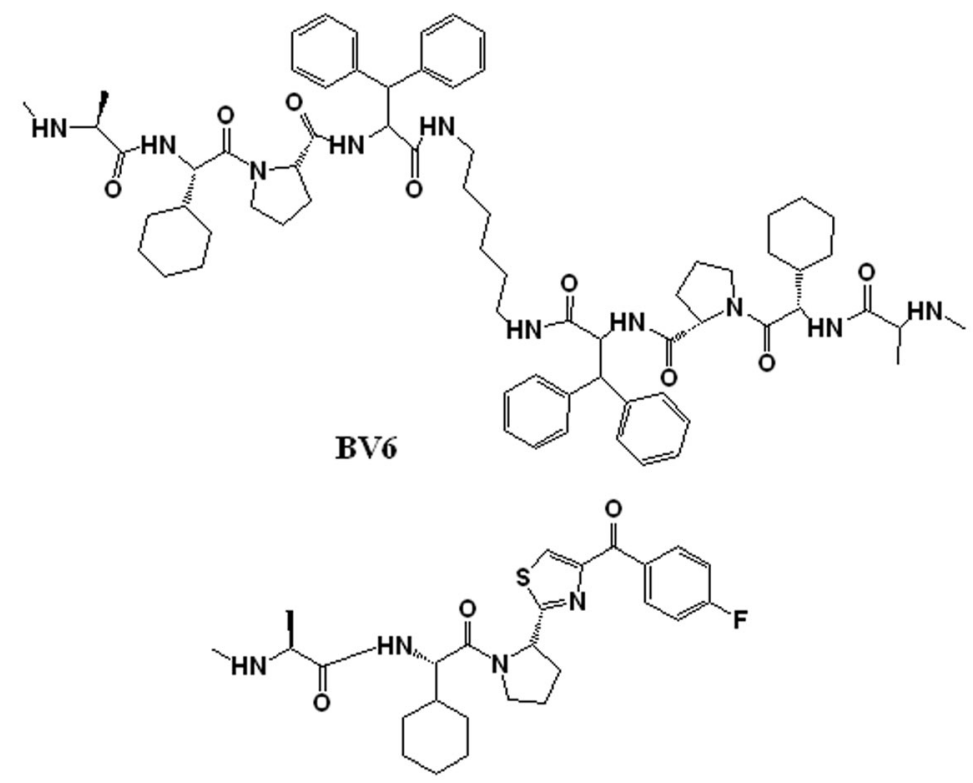

LC 161

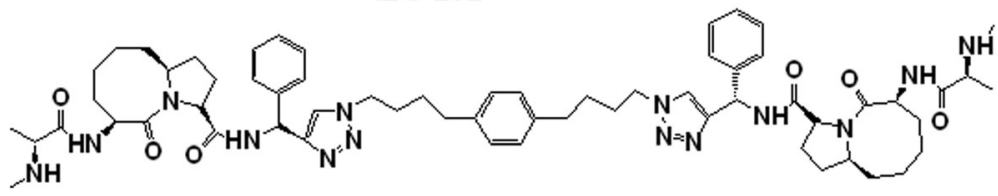

SM164

Fig. 3 Chemical structures of Smac mimetics BV6 (1), LC 161 (2) and SM164 (3)

human prostate adenocarcinoma (LNCaP-COX-2) and the control cell (LNCaP-Neo) was evaluated. LNCaP-COX-2 cells were more resistance to IR than LNCaP-Neo cells. Their results confirmed the radiosensitivity effect of diclofenac due to reduction the survival fractions at 2 Gy in presence of diclofenac (35.5\%) in comparison with radiation only (78.6\%) in LNCaP-COX-2 cells. Also, insignificant differences of radiosensitivity were found in LNCaP-Neo cells treated with diclofenac. Diclofenac has synergistic effect with IR through induction TRAIL-induced cell death that enhances the activation of caspase 8, caspase 9 and caspase 3. Delay in tumor growth was observed in combination of topical diclofenac gel and radiation than either radiation or diclofenac only [100]. Decrease the level of COX-2 expression by NS-398 as a selective COX-2 inhibitor led to amplyfing $\mathrm{G} 2 / \mathrm{M}$ phase arrest in irradiated melanoma cell lines WM35 and LU1205 and subsequently decrease in survival of melanoma cells [101]. The radiosensitivity effect of NS-398 was shown in human prostate carcinoma cells PC3 with expressing COX-2, not radiosensitivity effect was seen in COX-2 knockdown PC3 cells [102]. It was shown that curcumin induced radiosensitivity and apoptosis by inhibition of survivin and COX-2 and result to activation of the caspase 3 and down-regulation of prostaglandin E2 simultaneously [103-105]. The potential role of COX-2 inhibitor to enhance the efficacy of radiotherapy was reviewed recently [56].

Results of several studies have shown that induction of the caspase cascade pathway by radiotherapy other than enhancement of sensitization of tumor cells to effects of radiation might results in tumor cell re-population that will be discussed in the next section (Fig. 4) [14, 106, 107].

\section{Radiation-induced tumor cell repopulation: caspase 3-dependent activation of PLA2}

Phospholipazes A2 are membrane enzymes that hydrolyze acyl esters of phospholipids at the sn- 2 bond to produce arachidonic acid and lysophospholipids. These enzymes are commonly classified into secreted, cytosolic, lipoproteinassociated and $\mathrm{Ca}^{2+}$ independent PLA2s [108, 109]. Of these enzymes the $\mathrm{Ca}^{2+}$ independent PLA2s have numerous biological activities such as cell differentiation, cell proliferation, and cell death and it has been reported that changes in iPLA2 expression results in many disorders [108-110]. Results of investigation on human PLA2 structure have shown that this peptide has 806 amino acid, contains an ankyrin-repeat domain, a putative caspase-3 cleavage motifs and a catalytic site [109]. Cleavage of iPLA2 at Asp83 of TNF $\alpha /$ cycloheximide-treated U937 cells results in excessive release of fatty acids which implies caspase-3- 


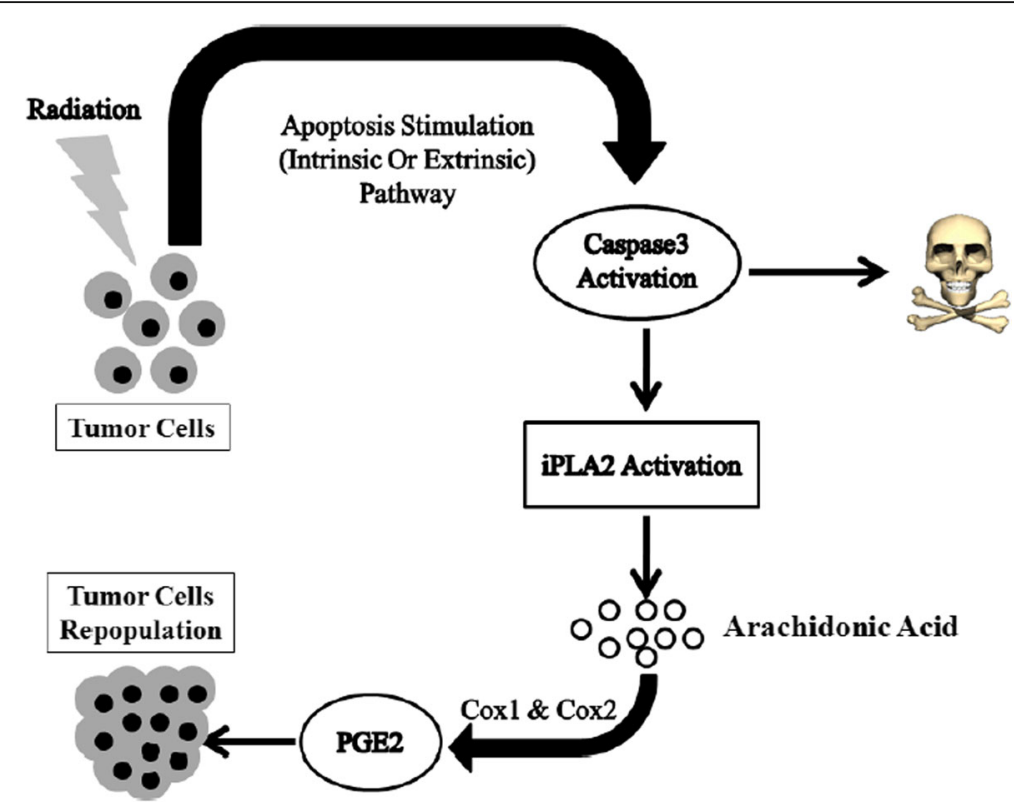

Fig. 4 A schematic representation of caspase activation resulting in cell death and tumor cell repopulation. Caspase 3 upregulation followed by apoptosis stimuli lead to iPLA2 (Ca(2+)-independent cytosolic phospholipase A2) activation and cell death. Hydrolysis of fatty acids by iPLA2 results in arachidonic acid release and production of PGE2 (Prostaglandin E2) a well-known product of cyclooxygenase enzymes which induce tumor cell repopulation

mediated activation of iPLA2 [109, 111]. This finding is important because induction of apoptosis by activation of caspase cascade might result in migration and proliferation of malignant cells. As an example it has been shown that caspase 3 facilitated growth of malignant cells by overexpression of iPLA2 [112]. Furthermore repopulation of surviving cancer cells, as a common obstacle, during the intervals between two doses of radiotherapy is mediated by caspase 3 [14]. It has been reported that upregulation of caspase 3 which is induced by radiation other than acting as an effector to mediate apoptosis, increases significantly recurrence of cancers and deaths. It has also been shown that the cells with high expression of executioner caspases cause wound healing and tissue regeneration through a pathway called "Phoenix Rising" [113, 114]. Actually activation of iPLA2, that could be caspase-3 mediated, generates PGE2 and promotes tumor repopulation (Fig. 4) [14, 113]. Molecular studies have shown that recruitment macrophages that govern elimination of apoptotic cells after radiotherapy induce tumor repopulation by production of a clearance-related cytokine milieu including PGE2 $[106,107,115]$. Results of a recent study showed that after radiotherapy, the increase in caspase 3 , caspase 7 and protein kinase $\mathrm{Cd}$ (PKCd) levels agitate the proliferation of surviving pancreatic tumor cells [106]. A remarkable reduction in recurrence of living cell as compared to wildtype pancreatic cells has been observed in combination therapy involving the use of radiation in dominantnegative mutants of caspase 3 (DN_C3), caspase 7 (DN_C7), or PKCd (DN_PKCS) [106].

\section{The effect of autophagy stimulators on tumor growth}

Autophagy induction is one strategy for reducing tumor cell repopulation and enhancement of cell death in cells non-expressing apoptotic regulatory proteins or resistance to multiple apoptotic stimuli $[116,117]$. Autophagy is another form of cell death that could negatively (e.g. mammalian target of rapamaycin (mTOR), Bcl-2) or positively (e.g. Beclin, ULK complex (Unc-51-like kinases) regulate [118]. Irradiation of $\mathrm{Bax}^{-} / \mathrm{Bak}^{-}$mouse embryonic fibroblasts (MEF) cells were accompanied with enhances the level of pro-autophagy proteins such as Becline-1 and ATG5-ATG12 complex. A markedly radiosensitizing effect was observed in $\mathrm{Bax}^{-} / \mathrm{Bak}^{-} \mathrm{MEF}$ cells that was mediated through autophagy induction. No radiosensitization response was found in MEF cell treated with 3-methyladenine (3-MA) as an inhibitor of autophagy. The radiosensitization effect was increased in cells treated with Rad001 as a mammalian target of rapamaycin (mTOR) inhibitor [119]. A significant enhancement in radiation efficacy was found in prostate cancer cells PC-3 and DU-145 treated with combination rapamaycin (mTORI) and Z-VAD (a caspase inhibitor) with IR [120]. A combination of Z-DEVD (a caspase-3 inhibitor) and radiation has been reported to enhance radiosenstization in a mouse with lung cancer by induction of autophagy pathway [115]. Delay in tumor growth and cellular proliferation (Ki67 staining), reduce angiogenesis (vWF staining) and apoptosis (TUNEL staining) confirmed this radiosensitizing effect that was mediated through induction autophagy. In summary, recruit of caspase inhibitor with 
radiation to stimulate autophagy pathway may be a useful strategy to increase survival times of patients and a remarkable delay in tumor recurrence.

The effect of dual COX-2 and EGFR inhibitor on tumor growth As previously discussed, there is a cross talk between dual COX-2 and EGFR pathways. Briefly, PGE2 could transactivate EGFR with several complex processes such as enhancement the expression of amphiregulin, AKT, ERK and sarcoma dependent pathways [60-62]. On the other hand, EGFR could enhance COX-2 expression in normal and tumor cells such as head and neck squamous cell carcinoma (HNSCC) cell line mainly through Ras/Raf/ MAPK $[121,122]$. Several studies suggested that combination treatment with EGFR and COX-2 inhibitor led to more antiangiogenic and antitumor activity with supraadditive reduction in the levels of multiple pro-survival proteins such as p-ERK1/2, p-EGFR, p-AKT, p-STAT3, COX-2 and PGE2. A synergistic inhibitory effect was shown by combination treatment with Iressa (EGFR tyrosin kinase inhibitor) and SC-236 (COX-2inhibitor) in human breast and colon cancer lines and in mice bearing colon cancer xenograft [123]. Choe et al. showed the same results in HNSCC in vitro and in vivo by combination treatment with celecoxib and Iressa [124]. Preclinical combined treatment with erlotinib (EGFR tryrosin kinase inhibitor) and cetuximab showed significant inhibition in growth of head and neck cancer cell and animal xenograft model. Tissue biopsy in preclinical study among patients that received simultaneously erlotinib and cetuximab to showed a remarkable down regulate in pro-survival pathways such as ERK and AKT [125]. A clinical study among 107 patients with nonsmall cell lung cancer that were received erlotinib plus celecoxib or placebo demonstrated that progression-free survival was improved between patients receive both erlotinib and celecoxib as compared to placebo group [126]. A supra additive effect in inhibition of clonogenic survival, apoptosis enhancement and tumor growth suppression was observed by simultaneously combination treatment with celecoxib (COX-2I), erlotinib (EGFR inhibitor) and IR in the HNSCC and phase I clinical study [127].

\section{Conclusion and perspectives}

Induction of apoptosis by IR and chemotherapeutic agents is a known strategy for killing human malignant cells. ROS that is produced during radiation therapy damage DNA and as a result trigger apoptotic pathway. Apoptosis induction through intrinsic and extrinsic pathways leads to caspase cascade activation. Also the mechanism of action of many radiosensitizers is based on caspase cascade activation. Caspase 3 act as an execuatior mediator in apoptosis, tumor repopulation through iPLA2 activation and PGE2 production. Repopulation of tumors results in failure of therapy. Release of PGE2 upregulates the level of expression of pro-survival proteins including: p-ERK1/2, p-EGFR, p-AKT, p-STAT3, COX-2 and PGE-2, which lead to apoptosis suppression and tumor proliferation. As a hypothesis, caspase 3 has a paradox role where its activation results in apoptosis and simultaneous acceleration of re-population of surviving tumor cells. Blockage of caspase 3 activity is a strategy to overcome radioresistance. On the other hand dependency between production of apoptosis mediator and increase in PGE2 and iPLA2 activity is a major reason for the treatment failure in radiotherapy. Results of investigations have shown that the use of COX-2 inhibitors may lead to more effective treatment. Furthermore the combination use of EGFR inhibitor and IR with COX-2 inhibitor is more impressive therapeutic regimen than the one without EGFR inhibitor. However, more clinical experiments are required to clarify the advantages of adjuvant use of cyclooxygenase, EGFR or caspase inhibitor in combination with radiotherapy (Fig. 5).

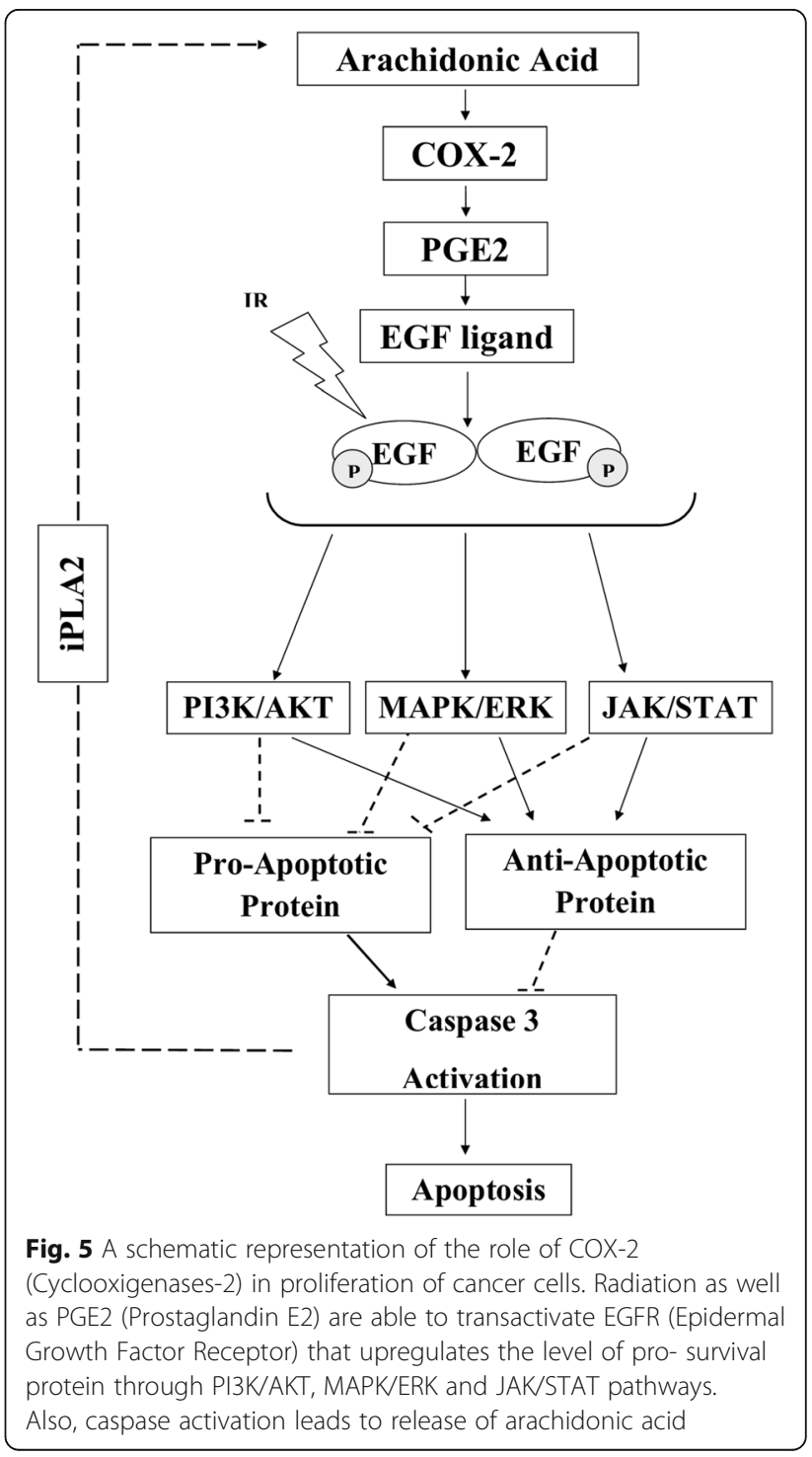




\section{Abbreviation}

APAF-1: Adapter Protein Apoptotic protease-activating Factor-1; AVPI peptide: Ala-Val-Pro-lle (AVPI) tetrapeptide; BIR3: Baculovirus IAP Repeat 3; C-IAP2: Baculoviral IAP repeat-containing protein3 (also known as CIAP2) is a protein that in humans is encoded by the BIRC3 gene; C-IAPI: Baculoviral IAP repeat-containing protein 2 (also known as CIAP1) is a protein that in humans is encoded by the BIRC2 gene; dATP: Deoxyadenosine triphosphate DIABLO: Direct Inhibitor of Apoptosis protein-Binding protein with low pl. DIABLO is also referred to as second mitochondria-derived activator of caspases or SMAC.; DN_C3: dominant-negative mutants of caspase 3; DN_C7: dominant-negative mutants of caspase 7; DN_PKC 8 : dominantnegative mutants of PKCd; ER: Endoplasmic reticulum; FADD: Fas-associating protein with a death domain; IAP: Inhibitors of apoptosis proteins; IPLA2: $\mathrm{Ca}(2$ +)-independent cytosolic phospholipase A2; Ip-PLA2: lipoprotein-associated PLA2s; mTOR: MammalianTtarget of Rapamaycin; NAIP: Baculoviral IAP repeat-containing protein 1 is a protein that in humans is encoded by the NAIP gene; NF-kB: nuclear factor kappa-light-chain-enhancer of activated B cells; PGE2: Prostaglandin E2; PKCd: Protein kinase $C$ delta type is an enzyme that in humans is encoded by the PRKCD gene; ROS: Reactive oxygen species; ULK complex: Serine/threonine-protein kinase ULK1 is an enzyme that in humans is encoded by the ULK1 gene; SMAC: Second mitochondria-derived activator of caspases; TNF: Tumor necrosis factor; TNFR1: Tumor necrosis factor receptor-1; TRAIL: TNF-relatedapoptosis-inducing ligand; XIAP: X-linked inhibitor of apoptosis protein (XIAP), also known as inhibitor of apoptosis protein 3 (IAP3) and baculoviral IAP repeat-containing protein 4 (BIRC), is a protein that stops apoptotic cell death. In humans, this protein (XIAP) is produced by a gene named XIAP gene located on the X chromosome; Z-DEVD: Caspase-3 inhibitor

\section{Acknowledgment}

Not applicable.

\section{Funding}

This review was not supported by any company.

\section{Availability of data and materials}

For preparation of this review, all data were studied and obtained from other published paper.

\section{Authors' contributions}

NR undertook writing, data interpretation and integration and design figures. AK undertook writing and editing. SJH undertook design and supervised it. All authors read and approved the final manuscript.

\section{Competing interests}

The authors declare that they have no competing interests.

\section{Consent for publication}

Authors have agreed to submit it in its current form for consideration for publication in the Journal.

\section{Ethics approval and consent to participate}

Not applicable.

\section{Author details}

'Department of Radiopharmacy, Faculty of Pharmacy, Tehran University of Medical Sciences, Tehran, Iran. ${ }^{2}$ Department of Radiopharmacy, Faculty of Pharmacy, Mazandaran University of Medical Sciences, Sari, Iran. ${ }^{3}$ Department of Medicinal Chemistry, Faculty of Pharmacy, Tehran University of Medical Sciences, Tehran, Iran.

Received: 18 November 2016 Accepted: 30 November 2016 Published online: 07 December 2016

\section{References}

1. Hosseinimehr SJ. The use of angiotensin II receptor antagonists to increase the efficacy of radiotherapy in cancer treatment. Future Oncol. 2014;10(15):2381-90.

2. Bernier J, Hall EJ, Giaccia A. Radiation oncology: a century of achievements. Nat Rev Cancer. 2004;4(9):737-47.

3. Eriksson D, Stigbrand T. Radiation-induced cell death mechanisms. Tumor Biol. 2010;31(4):363-72.
4. Ouyang L, Shi Z, Zhao S, Wang FT, Zhou TT, et al. Programmed cell death pathways in cancer: a review of apoptosis, autophagy and programmed necrosis. Cell Prolif. 2012;45(6):487-98.

5. Palumbo S, Comincini S. Autophagy and ionizing radiation in tumors: the "survive or not survive" dilemma. J Cell Physiol. 2013;228(1):1-8.

6. Rupnow BA, Knox SJ. The role of radiation-induced apoptosis as a determinant of tumor responses to radiation therapy. Apoptosis. 1999;4(2):115-43.

7. Lichter AS, Lawrence TS. Recent advances in radiation oncology. N Engl J Med. 1995;332(6):371-9.

8. Abdi K, Khalaj A, Ostad SN, Lamei N, Khoshayand MR. Synthesis, in vitro aerobic and hypoxic cytotoxicity and radiosensitizing activity of novel metronidazole tethered 5-fluorouracil. Daru. 2013;21(1):76.

9. Balcer-Kubiczek EK. Apoptosis in radiation therapy: a double-edged sword. Exp Oncol. 2012;34(3):277-85.

10. Kim JJ, Tannock IF. Repopulation of cancer cells during therapy: an important cause of treatment failure. Nat Rev Cancer. 2005;5(7):516-25.

11. Taylor RC, Cullen SP, Martin SJ. Apoptosis: controlled demolition at the cellular level. Nat Rev Mol Cell Biol. 2008;9(3):231-41.

12. Zahmatkesh $\mathrm{MH}$, Hosseinimehr $\mathrm{SJ}$, Mahdiuni H. Role of CHK2 inhibitors in the cellular responses to ionizing radiation. Mini Rev Med Chem. 2014;14(10):812-8.

13. de Bruin EC, Medema JP. Apoptosis and non-apoptotic deaths in cancer development and treatment response. Cancer Treat Rev. 2008;34(8):737-49.

14. Huang Q, Li F, Liu X, Li W, Shi W, et al. Caspase 3-mediated stimulation of tumor cell repopulation during cancer radiotherapy. Nat Med. 2011;17(7):860-6.

15. Shi Y. Caspase activation, inhibition, and reactivation: a mechanistic view. Protein Sci. 2004;13(8):1979-87.

16. Shi Y. Caspase activation: revisiting the induced proximity model. Cell. 2004; 117(7):855-8.

17. Mcllwain DR, Berger T, Mak TW. Caspase functions in cell death and disease. Cold Spring Harb Perspect Biol. 2013;5(4):a008656.

18. Chipuk J, Bouchier-Hayes L, Green D. Mitochondrial outer membrane permeabilization during apoptosis: the innocent bystander scenario. Cell Death Differ. 2006;13(8):1396-402.

19. Yang XH, Edgerton S, Thor AD. Reconstitution of caspase-3 sensitizes MCF-7 breast cancer cells to radiation therapy. Int J Oncol. 2005;26(6):1675-80.

20. Ramp U, Caliskan E, Mahotka C, Krieg A, Heikaus S, et al. Apoptosis induction in renal cell carcinoma by TRAlL and $\psi$-radiation is impaired by deficient caspase-9 cleavage. Br J Cancer. 2003:88(11):1800-7.

21. Essmann F, Engels $I H$, Totzke $G$, Schulze-Osthoff $K$, Jänicke RU. Apoptosis resistance of MCF-7 breast carcinoma cells to ionizing radiation is independent of p53 and cell cycle control but caused by the lack of caspase-3 and a caffeine-inhibitable event. Cancer Res. 2004;64(19):7065-72.

22. Budihardjo I, Oliver H, Lutter M, Luo X, Wang X. Biochemical pathways of caspase activation during apoptosis. Annu Rev Cell Dev Biol. 1999;15(1):269-90.

23. Mathiasen IS, Lademann U, Jäättelä M. Apoptosis induced by vitamin D compounds in breast cancer cells is inhibited by $\mathrm{Bcl}-2$ but does not involve known caspases or p53. Cancer Res. 1999;59(19):4848-56.

24. Chipuk JE, Fisher JC, Dillon CP, Kriwacki RW, Kuwana T, et al. Mechanism of apoptosis induction by inhibition of the anti-apoptotic BCL-2 proteins. Proc Natl Acad Sci. 2008;105(51):20327-32.

25. Deveraux QL, Reed JC. IAP family proteins-suppressors of apoptosis. Genes Dev. 1999;13(3):239-52.

26. Golden E, Pellicciotta I, Demaria S, Barcellos-Hoff MH, Formenti SC. The convergence of radiation and immunogenic cell death signaling pathways. Front Oncol. 2012;2:88

27. Roos WP, Kaina B. DNA damage-induced cell death: from specific DNA lesions to the DNA damage response and apoptosis. Cancer Lett. 2013;332(2):237-48.

28. Smith J, Mun Tho L, Xu N, Gillespie DA. The ATM-Chk2 and ATR-Chk1 pathways in DNA damage signaling and cancer. Adv Cancer Res. 2010;108(C):73-112.

29. Efeyan A, Serrano M. p53: guardian of the genome and policeman of the oncogenes. Cell Cycle. 2007;6(9):1006-10.

30. Pflaum J, Schlosser S, Müller M. p53 family and cellular stress responses in cancer, Molecular mechanisms of cellular stress responses in cancer and their therapeutic implications. 2007. p. 47.

31. Clarke A, Purdie C, Harrison D, Morris R. Thymocyte apoptosis induced by p53-dependent and. Nature. 1993;362:29.

32. Yonish-Rouach E, Resnftzky D, Lotem J, Sachs L, Kimchi A, et al. Wild-type p53 induces apoptosis of myeloid leukaemic cells that is inhibited by interleukin-6. 1991.

33. Shaw P, Bovey R, Tardy S, Sahli R, Sordat B, et al. Induction of apoptosis by wild-type p53 in a human colon tumor-derived cell line. Proc Natl Acad Sci. 1992;89(10):4495-9. 
34. Flores ER, Tsai KY, Crowley D, Sengupta S, Yang A, et al. p63 and p73 are required for p53-dependent apoptosis in response to DNA damage. Nature. 2002:416(6880):560-4.

35. Maier P, Hartmann L, Wenz F, Herskind C. Cellular Pathways in Response to Ionizing Radiation and Their Targetability for Tumor Radiosensitization. Int J Mol Sci. 2016;17(1):102

36. Sheard MA. lonizing radiation as a response-enhancing agent for CD95mediated apoptosis. Int J Cancer. 2001;96(4):213-20.

37. Ogura A, Oowada S, Kon Y, Hirayama A, Yasui H, et al. Redox regulation in radiation-induced cytochrome $\mathrm{C}$ release from mitochondria of human lung carcinoma A549 cells. Cancer Lett. 2009;277(1):64-71.

38. Kolesnick $\mathrm{R}$. The therapeutic potential of modulating the ceramide/ sphingomyelin pathway. J Clin Invest. 2002;110(1):3-8.

39. Okazaki T, Bell R, Hannun Y. Sphingomyelin turnover induced by vitamin D3 in HL-60 cells. Role in cell differentiation. J Biol Chem. 1989:264(32):19076-80.

40. Liao W-C, Haimovitz-Friedman A, Persaud RS, McLoughlin M, Ehleiter D, et al. Ataxia telangiectasia-mutated gene product inhibits DNA damage-induced apoptosis via ceramide synthase. J Biol Chem. 1999;274(25):17908-17.

41. Navolanic PM, Steelman LS, McCubrey JA. EGFR family signaling and its association with breast cancer development and resistance to chemotherapy (Review). Int J Oncol. 2003;22(2):237-52.

42. Hein AL, Ouellette MM, Yan Y. Radiation-induced signaling pathways that promote cancer cell survival (review). Int J Oncol. 2014;45(5):1813-9.

43. Bonni A, Brunet A, West AE, Datta SR, Takasu MA, et al. Cell survival promoted by the Ras-MAPK signaling pathway by transcription-dependent and-independent mechanisms. Science. 1999;286(5443):1358-62.

44. Ewings KE, Hadfield-Moorhouse K, Wiggins CM, Wickenden JA, Balmanno K, et al. ERK1/2-dependent phosphorylation of BimEL promotes its rapid dissociation from Mcl-1 and BCl-xL. EMBO J. 2007;26(12):2856-67.

45. Allan LA, Morrice N, Brady S, Magee G, Pathak S, et al. Inhibition of caspase-9 through phosphorylation at Thr 125 by ERK MAPK. Nat Cell Biol. 2003:5(7):647-54.

46. Yamaguchi $\mathrm{H}$, Wang $\mathrm{HG}$. The protein kinase PKB/Akt regulates cell survival and apoptosis by inhibiting Bax conformational change. Oncogene. 2001; 20(53):7779-86.

47. Soltoff SP, Carraway KL, Prigent S, Gullick W, Cantley LC. ErbB3 is involved in activation of phosphatidylinositol 3-kinase by epidermal growth factor. Mol Cell Biol. 1994;14(6):3550-8.

48. Marone R, Cmiljanovic V, Giese B, Wymann MP. Targeting phosphoinositide 3-kinase-moving towards therapy. Biochimica et Biophysica Acta (BBA)Proteins and. Proteomics. 2008;1784(1):159-85.

49. Yang J-Y, Xia W, Hu M. lonizing radiation activates expression of FOXO3a, Fas ligand, and Bim, and induces cell apoptosis. Int J Oncol. 2006;29(3):643-8.

50. Ozes ON, Mayo LD, Gustin JA, Pfeffer SR, Pfeffer LM, et al. NF-kB activation by tumour necrosis factor requires the Akt serine-threonine kinase. Nature. 1999;401(6748):82-5

51. Dan HC, Sun M, Kaneko S, Feldman RI, Nicosia SV, et al. Akt phosphorylation and stabilization of X-linked inhibitor of apoptosis protein (XIAP). J Biol Chem. 2004;279(7):5405-12.

52. Fumarola C, Bonelli MA, Petronini PG, Alfieri RR. Targeting PI3K/AKT/mTOR pathway in non small cell lung cancer. Biochem Pharmacol. 2014;90(3):197-207.

53. Engström M, Karlsson R, Jönsson $\mathrm{J}-\mathrm{I}$. Inactivation of the forkhead transcription factor FoxO3 is essential for PKB-mediated survival of hematopoietic progenitor cells by kit ligand. Exp Hematol. 2003;31(4):316-23.

54. Loberg RD, Vesely E, Brosius FC. Enhanced glycogen synthase kinase-3 $\beta$ activity mediates hypoxia-induced apoptosis of vascular smooth muscle cells and is prevented by glucose transport and metabolism. J Biol Chem. 2002;277(44):41667-73.

55. Toulany M, Kehlbach R, Florczak U, Sak A, Wang S, et al. Targeting of AKT1 enhances radiation toxicity of human tumor cells by inhibiting DNA-PKcsdependent DNA double-strand break repair. Mol Cancer Ther. 2008;7(7):1772-81.

56. Salehifar $E_{1}$ Hosseinimehr SJ. The use of cyclooxygenase-2 inhibitors for improvement of efficacy of radiotherapy in cancers. Drug Discov Today. 2016;21(4):654-62.

57. Yu H, Kortylewski M, Pardoll D. Crosstalk between cancer and immune cells: role of STAT3 in the tumour microenvironment. Nat Rev Immunol. 2007;7(1):41-51.

58. Ristimäki A, Sivula A, Lundin J, Lundin M, Salminen T, et al. Prognostic significance of elevated cyclooxygenase-2 expression in breast cancer. Cancer Res. 2002;62(3):632-5.

59. Secchiero P, Barbarotto E, Gonelli A, Tiribelli M, Zerbinati C, et al. Potential pathogenetic implications of cyclooxygenase-2 overexpression in B chronic lymphoid leukemia cells. Am J Pathol. 2005;167(6):1599-607.
60. Sobolewski C, Cerella C, Dicato M, Ghibelli L, Diederich M. The role of cyclooxygenase-2 in cell proliferation and cell death in human malignancies. Int J Cell Biol. 2010;2010:215158. doi:10.1155/2010/215158.

61. Laube M, Kniess T, Pietzsch J. Development of Antioxidant COX-2 Inhibitors as Radioprotective Agents for Radiation Therapy-A Hypothesis-Driven Review. Antioxidants. 2016:5(2):14.

62. Yamaki T, Endoh K, Miyahara M, Nagamine I, Huong NTT, et al. Prostaglandin E 2 activates Src signaling in lung adenocarcinoma cell via EP 3. Cancer Lett. 2004;214(1):115-20.

63. Ju GZ, Shen B, Sun SL, Yan FQ, Fu SB. Effect of X-rays on expression of caspase-3 and p53 in EL-4 cells and its biological implications. Biomed Environ Sci. 2007;20(6):456-9.

64. Hosokawa Y, Sakakura Y, Tanaka L, Okumura K, Yajima T, et al. Radiationinduced apoptosis is independent of caspase- 8 but dependent on cytochrome $\mathrm{c}$ and the caspase-9 cascade in human leukemia HL60 cells. J Radiat Res. 2005;46(3):293-303.

65. Marini P, Budach W, Niyazi M, Junginger D, Stickl S, et al. Combination of the pro-apoptotic TRAIL-receptor antibody mapatumumab with ionizing radiation strongly increases long-term tumor control under ambient and hypoxic conditions. Int J Radiat Oncol Biol Phys. 2009;75(1):198-202.

66. Marini P, Denzinger S, Schiller D, Kauder S, Welz S, et al. Combined treatment of colorectal tumours with agonistic TRAIL receptor antibodies HGS-ETR1 and HGS-ETR2 and radiotherapy: enhanced effects in vitro and dose-dependent growth delay in vivo. Oncogene. 2006;25(37):5145-54.

67. Marini P, Jendrossek V, Durand E, Gruber C, Budach W, et al. Molecular requirements for the combined effects of TRAIL and ionising radiation. Radiother Oncol. 2003;68(2):189-98.

68. Marini $P$, Junginger D, Stickl S, Budach W, Niyazi M, et al. Combined treatment with lexatumumab and irradiation leads to strongly increased long term tumour control under normoxic and hypoxic conditions. Radiat Oncol. 2009;4:49.

69. Abdi K, Khalaj A, Ostad S-N, Khoshayand MR. Cytotoxicity and radiosensitising activity of synthesized dinitrophenyl derivatives of 5fluorouracil. DARU J Pharm Sci. 2012;20(1):1.

70. Khalaj A, Doroudi AR, Ostad SN, Khoshayand MR, Babai M, et al. Synthesis, aerobic cytotoxicity, and radiosensitizing activity of novel 2, 4dinitrophenylamine tethered 5-fluorouracil and hydroxyurea. Bioorg Med Chem Lett. 2006;16(23):6034-8.

71. Khalaj A, Abdi K, Ostad SN, Khoshayand MR, Lamei N, et al. Synthesis, In Vitro Cytotoxicity and Radiosensitizing Activity of Novel 3-[(2, 4Dinitrophenylamino) Alkyl] Derivatives of 5-Fluorouracil. Chem Biol Drug Des. 2014;83(2):183-90.

72. Abdi K, Khalaj A, Ostad SN, Lamei N, Khoshayand MR. Synthesis, in vitro aerobic and hypoxic cytotoxicity and radiosensitizing activity of novel metronidazole tethered 5-fluorouracil. DARU J Pharm Sci. 2013;21(1):1.

73. Cho HJ, Ahn KC, Choi JY, Hwang SG, Kim WJ, et al. Luteolin acts as a radiosensitizer in non-small cell lung cancer cells by enhancing apoptotic cell death through activation of a p38/ROS/caspase cascade. Int J Oncol. 2015;46(3):1149-58.

74. Zhang Q, Wan L, Guo Y, Cheng N, Cheng W, et al. Radiosensitization effect of luteolin on human gastric cancer SGC-7901 cells. J Biol Regul Homeost Agents. 2009;23(2):71-8.

75. Nair S, Nair RRK, Srinivas P, Srinivas G, Pillai MR. Radiosensitizing effects of plumbagin in cervical cancer cells is through modulation of apoptotic pathway. Mol Carcinog. 2008;47(1):22-33.

76. Cai Q, Sun H, Peng Y, Lu J, Nikolovska-Coleska Z, et al. A potent and orally active antagonist (SM-406/AT-406) of multiple inhibitor of apoptosis proteins (IAPs) in clinical development for cancer treatment. J Med Chem. 2011;54(8):2714-26.

77. Beug ST, Tang VA, LaCasse EC, Cheung HH, Beauregard CE, et al. Smac mimetics and innate immune stimuli synergize to promote tumor death. Nat Biotechnol. 2014;32(2):182-90.

78. Fulda S, Vucic D. Targeting IAP proteins for therapeutic intervention in cancer. Nat Rev Drug Discov. 2012;11(2):109-24.

79. Fulda S. Targeting IAP, proteins in combination with radiotherapy. Radiat Oncol. 2015;10(1):105.

80. Liu N, Tao Z, Blanc JM, Zaorsky NG, Sun Y, et al. Debio 1143, an antagonist of multiple inhibitor-of-apoptosis proteins, activates apoptosis and enhances radiosensitization of non-small cell lung cancer cells in vitro. Am J Cancer Res. 2014:4(6):943-51.

81. Oost TK, Sun C, Armstrong RC, Al-Assaad AS, Betz SF, et al. Discovery of potent antagonists of the antiapoptotic protein XIAP for the treatment of cancer. J Med Chem. 2004;47(18):4417-26. 
82. Vellanki SH, Grabrucker A, Liebau S, Proepper C, Eramo A, et al. Smallmolecule XIAP inhibitors enhance gamma-irradiation-induced apoptosis in glioblastoma. Neoplasia. 2009;11(8):743-52.

83. Berger $\mathrm{R}$, Jennewein C, Marschall V, Karl S, Cristofanon S, et al. NF-kappaB is required for Smac mimetic-mediated sensitization of glioblastoma cells for gamma-irradiation-induced apoptosis. Mol Cancer Ther. 2011;10(10):1867-75.

84. de Almagro MC, Vucic D. The inhibitor of apoptosis (IAP) proteins are critical regulators of signaling pathways and targets for anti-cancer therapy. Exp Oncol. 2012;34(3):200-11.

85. Qin Q, Zuo Y, Yang X, Lu J, Zhan L, et al. Smac mimetic compound LCL161 sensitizes esophageal carcinoma cells to radiotherapy by inhibiting the expression of inhibitor of apoptosis protein. Tumour Biol. 2014;35(3):2565-74.

86. Lu J, Bai L, Sun H, Nikolovska-Coleska Z, McEachern D, et al. SM-164: a novel, bivalent Smac mimetic that induces apoptosis and tumor regression by concurrent removal of the blockade of CIAP-1/2 and XIAP. Cancer Res. 2008; 68(22):9384-93.

87. Yang D, Zhao Y, Li AY, Wang S, Wang G, et al. Smac-mimetic compound SM-164 induces radiosensitization in breast cancer cells through activation of caspases and induction of apoptosis. Breast Cancer Res Treat. 2012;133(1): 189-99

88. Yang J, McEachern D, Li W, Davis MA, Li H, et al. Radiosensitization of head and neck squamous cell carcinoma by a SMAC-mimetic compound, SM164, requires activation of caspases. Mol Cancer Ther. 2011;10(4):658-69.

89. Jalal Hosseinimehr S, Inanami O, Hamasu T, Takahashi M, Kashiwakura I, et al. Activation of c-kit by stem cell factor induces radioresistance to apoptosis through ERK-dependent expression of survivin in HL60 cells. J Radiat Res. 2004;45(4):557-61.

90. Lu B, Mu Y, Cao C, Zeng F, Schneider S, et al. Survivin as a therapeutic target for radiation sensitization in lung cancer. Cancer Res. 2004;64(8): 2840-5

91. Cao C, Mu Y, Hallahan DE, Lu B. XIAP and survivin as therapeutic targets for radiation sensitization in preclinical models of lung cancer. Oncogene. 2004; 23(42):7047-52.

92. Sah NK, Munshi A, Hobbs M, Carter BZ, Andreeff M, et al. Effect of downregulation of survivin expression on radiosensitivity of human epidermoid carcinoma cells. Int J Radiat Oncol Biol Phys. 2006;66(3):852-9.

93. Pennati M, Binda M, Colella G, Folini M, Citti L, et al. Radiosensitization of human melanoma cells by ribozyme-mediated inhibition of survivin expression. J Invest Dermatol. 2003;120(4):648-54.

94. Kami K, Doi R, Koizumi M, Toyoda E, Mori T, et al. Downregulation of survivin by siRNA diminishes radioresistance of pancreatic cancer cells. Surgery. 2005;138(2):299-305.

95. Kappler M, Taubert H, Bartel F, Blumke K, Panian M, et al. Radiosensitization, after a combined treatment of survivin siRNA and irradiation, is correlated with the activation of caspases 3 and 7 in a wt-p53 sarcoma cell line, but not in a mt-p53 sarcoma cell line. Oncol Rep. 2005;13(1):167-72.

96. Khan Z, Khan N, Tiwari RP, Patro IK, Prasad GB, et al. Down-regulation of survivin by oxaliplatin diminishes radioresistance of head and neck squamous carcinoma cells. Radiother Oncol. 2010;96(2):267-73.

97. Saha D, Choy H. Potential for combined modality therapy of cyclooxygenase inhibitors and radiation. Prog Exp Tum Res. Basel: Karger. 2003;37:193-209.

98. Grimes KR, Warren GW, Fang F, Xu Y, StClair WH. Cyclooxygenase-2 inhibitor, nimesulide, improves radiation treatment against non-small cell lung cancer both in vitro and in vivo. Oncol Rep. 2006;16(4):771-6.

99. Yusup G, Akutsu Y, Mutallip M, Qin W, Hu X, et al. A COX-2 inhibitor enhances the antitumor effects of chemotherapy and radiotherapy for esophageal squamous cell carcinoma. Int J Oncol. 2014;44(4):1146-52.

100. Inoue T, Anai S, Onishi S, Miyake M, Tanaka N, et al. Inhibition of COX-2 expression by topical diclofenac enhanced radiation sensitivity via enhancement of TRAIL in human prostate adenocarcinoma xenograft model. BMC Urol. 2013;13(1):1.

101. Johnson GE, Ivanov VN, Hei TK. Radiosensitization of melanoma cells through combined inhibition of protein regulators of cell survival. Apoptosis. 2008;13(6):790-802.

102. Palayoor ST, Arayankalayil MJ, Shoaibi A, Coleman CN. Radiation sensitivity of human carcinoma cells transfected with small interfering RNA targeted against cyclooxygenase-2. Clin Cancer Res. 2005;11(19):6980-6.

103. Lev-Ari S, Maimon Y, Strier L, Kazanov D, Arber N. Down-regulation of prostaglandin E2 by curcumin is correlated with inhibition of cell growth and induction of apoptosis in human colon carcinoma cell lines. J Soc Integr Oncol. 2006;4(1):21-6.
104. Jagetia GC. Radioprotection and radiosensitization by curcumin. Adv Exp Med Biol. 2007;595:301-20.

105. Hosseinimehr SJ. A review of preventive and therapeutic effects of curcumin in patients with cancer. J Clin Excell. 2014;2(2):13.

106. Cheng J, Tian L, Ma J, Gong Y, Zhang Z, et al. Dying tumor cells stimulate proliferation of living tumor cells via caspase-dependent protein kinase Cdelta activation in pancreatic ductal adenocarcinoma. Mol Oncol. 2015;9(1):105-14.

107. Lauber K, Munoz LE, Berens C, Jendrossek V, Belka C, et al. Apoptosis induction and tumor cell repopulation: the yin and yang of radiotherapy. Radiat Oncol. 2011;6:176.

108. Winstead MV, Balsinde J, Dennis EA. Calcium-independent phospholipase $A(2)$ : structure and function. Biochim Biophys Acta. 2000;1488(1-2):28-39.

109. Zhao X, Wang D, Zhao Z, Xiao Y, Sengupta S, et al. Caspase-3-dependent activation of calcium-independent phospholipase A2 enhances cell migration in non-apoptotic ovarian cancer cells. J Biol Chem. 2006;281(39):29357-68.

110. Ramanadham S, Ali T, Ashley JW, Bone RN, Hancock WD, Lei X. Calciumindependent phospholipases A2 and their roles in biological processes and diseases. J Lipid Res. 2015;56(9):1643-68.

111. Atsumi G, Murakami M, Kojima K, Hadano A, Tajima M, et al. Distinct roles of two intracellular phospholipase A2s in fatty acid release in the cell death pathway. Proteolytic fragment of type IVA cytosolic phospholipase A2alpha inhibits stimulus-induced arachidonate release, whereas that of type VI Ca2 + -independent phospholipase A2 augments spontaneous fatty acid release. J Biol Chem. 2000;275(24):18248-58.

112. Mao P, Smith L, Xie W, Wang M. Dying endothelial cells stimulate proliferation of malignant glioma cells via a caspase 3-mediated pathway. Oncol Lett. 2013;5(5):1615-20.

113. Li F, Huang Q, Chen J, Peng Y, Roop DR, Li F, Huang Q, Chen J, Peng Y, Roop $D R$, et al. Apoptotic cells activate the "phoenix rising" pathway to promote wound healing and tissue regeneration. Sci Signal. 2010;3(110):ra13.

114. Zimmerman MA, Huang Q, Li F, Liu X, Li CY. Cell death-stimulated cell proliferation: A tissue regeneration mechanism usurped by tumors during radiotherapy. Semin Radiat Oncol. 2013;23(4):288-95.

115. Kim KW, Hwang M, Moretti L, Jaboin JJ, Cha Yl, et al. Autophagy upregulation by inhibitors of caspase- 3 and mTOR enhances radiotherapy in a mouse model of lung cancer. Autophagy. 2008:4(5):659-68.

116. Fulda S. Autophagy and cell death. Autophagy. 2012;8(8):1250-1.

117. Buytaert E, Callewaert G, Vandenheede J, Agostinis P. Deficiency in apoptotic effectors Bax and Bak reveals an autophagic cell death pathway initiated by photodamage to the endoplasmic reticulum. Autophagy. 2006; 2(3):238-40.

118. He C, Klionsky DJ. Regulation mechanisms and signaling pathways of autophagy. Annu Rev Genet. 2009;43:67.

119. Kim KW, Mutter RW, Cao C, Albert JM, Freeman M, et al. Autophagy for cancer therapy through inhibition of pro-apoptotic proteins and mammalian target of rapamycin signaling. J Biol Chem. 2006;281(48):36883-90.

120. Cao C, Subhawong T, Albert JM, Kim KW, Geng L, et al. Inhibition of mammalian target of rapamycin or apoptotic pathway induces autophagy and radiosensitizes PTEN null prostate cancer cells. Cancer Res. 2006;66(20):10040-7.

121. Yoon JH, Higuchi H, Werneburg NW, Kaufmann SH, Gores GJ. Bile acids induce cyclooxygenase-2 expression via the epidermal growth factor receptor in a human cholangiocarcinoma cell line. Gastroenterology. 2002; 122(4):985-93.

122. Choe MS, Zhang X, Shin HJC, Shin DM. Interaction between epidermal growth factor receptor-and cyclooxygenase 2-mediated pathways and its implications for the chemoprevention of head and neck cancer. Mol Cancer Ther. 2005;4(9):1448-55.

123. Tortora G, Caputo R, Damiano V, Melisi D, Bianco R, et al. Combination of a selective cyclooxygenase-2 inhibitor with epidermal growth factor receptor tyrosine kinase inhibitor ZD1839 and protein kinase A antisense causes cooperative antitumor and antiangiogenic effect. Clin Cancer Res. 2003;9(4):1566-72.

124. Zhang X, Li M, Wang Z, Wieand HS, Grandis JR, et al. Simultaneously targeting epidermal growth factor receptor tyrosine kinase and cyclooxygenase-2, an efficient approach to inhibition of squamous cell carcinoma of the head and neck. Clin Cancer Res. 2004;10(17):5930-9.

125. Shin DM, Zhang H, Saba NF, Chen AY, Nannapaneni S, et al. Chemoprevention of head and neck cancer by simultaneous blocking of epidermal growth factor receptor and cyclooxygenase-2 signaling pathways: preclinical and clinical studies. Clin Cancer Res. 2013;19(5):1244-56. 
126. Gitlitz BJ, Bernstein E, Santos ES, Otterson GA, Milne G, et al. A randomized, placebo-controlled, multicenter, biomarker-selected, Phase 2 study of apricoxib in combination with erlotinib in patients with advanced non-small-cell lung cancer. J Thorac Oncol. 2014;9(4):577-82.

127. Fu S, Rivera M, Ko EC, Sikora AG, Chen $C T, V u$ HL, et al. Combined inhibition of epidermal growth factor receptor and cyclooxygenase-2 as a novel approach to enhance radiotherapy. J Cell Sci Ther. 2011;1(2):S1-002.

Submit your next manuscript to BioMed Central and we will help you at every step:

- We accept pre-submission inquiries

- Our selector tool helps you to find the most relevant journal

- We provide round the clock customer support

- Convenient online submission

- Thorough peer review

- Inclusion in PubMed and all major indexing services

- Maximum visibility for your research

Submit your manuscript at www.biomedcentral.com/submit
Biomed Central 